\title{
Lideranças femininas nas Folias de Reis, nas Umbandas e Candomblé: uma análise de fluxos e refluxos
}

\author{
Female leaders in Folias de Reis and Umbandas and Candomblé: an analysis of \\ ebb and flow
}

Andiara Barbosa Neder ${ }^{+}$

Gilciana Paulo Franco

RESUMO

\begin{abstract}
De cunho popular e devocional, a Folia de Reis era uma festa exclusivamente masculina. Entretanto, a mulher sempre esteve inserida, mas nas funções invisibilizadas. Atualmente, elas buscam sua inserção também na esfera ritual, e surgem as folionas e donas de folias. Não por coincidência, dentre os grupos pesquisados, aqueles liderados por mulheres são de pertença umbandista. Por outro lado, nas religiões afro-brasileiras a tradicional liderança feminina vem perdendo espaço. $O$ objetivo deste trabalho é discutir a relação inversa observada entre o aumento gradativo de autonomia e visibilidade femininas no universo androcêntrico da Folia de Reis e a paulatina perda de relevância no cenário atual da Umbanda e Candomblé, que historicamente contaram com a participação feminina efetiva.
\end{abstract}

Palavras-chave: Mulher, Folia de Reis, Umbanda, Candomblé.

\section{ABSTRACT}

Popular and devotional in nature, the Folia de Reis was an all-male party. However, the woman has always been inserted, but in invisible functions. Nowadays, they seek their insertion also in the ritual sphere, and arise the folly and owners of folias. Not coincidentally, among the groups surveyed, those led by women are of Umbanda membership. On the other hand, in Afro-Brazilian religions, traditional female leadership has been losing ground. The objective of this paper is to discuss the inverse relationship observed between the gradual increase of female autonomy and visibility in the androcentric universe of Folia de Reis and the gradual loss of relevance in the current scenario of Umbanda and Candomblé, which historically counted on effective female participation.

Keywords: Woman, Folia de Reis, Umbanda, Candomblé.

1Doutoranda em Ciência da Religião pelo Programa de Pós-graduação em Ciência da Religião, Universidade Federal de Juiz de Fora. Artigo recebido em 31.07.2019 e aprovado em 29.11.2019. Contato: andiaraneder@yahoo.com.br

2Doutora em Ciência da Religião, pelo Programa de Pós-graduação em Ciência da Religião, Universidade Federal de Juiz de Fora. Artigo recebido 31.07.2019 e aprovado em 29.11.2019. Contato: gilcifranco@yahoo.com.br 


\section{INTRODUÇÃO}

Este artigo tem por objetivo traçar reflexões que levem à compreensão de como vêm ocorrendo em contextos religiosos deslocamentos na direção contrária do que acena cada tradição em relação ao papel da mulher nesses ambientes. Como as mulheres estão ganhando espaço em ambientes religiosos tradicionalmente androcêntricos e perdendo onde a matrilinearidade era tradicionalmente uma realidade quase hegemônica dentre as lideranças religiosas. Este texto aborda dois contextos religiosos aparentemente autônomos, mas quando se investiga suas raízes identitárias é possível perceber entrecruzamentos de elementos e uma porosidade de cosmovisões nos subterrâneos híbridos da estrutura sociocultural, que possibilitou a emergência de realidades diversas do que a tradição consideraria natural, ou que tenha se tornado naturalizado. Pode-se pensar que as tendências de igualdade estejam tentando se impor em um fluxo de transmissão de poder, de onde tem mais para onde tem menos. Por um lado, é possivel observar esse fluxo com o aumento do alcance das ideias feministas que se disseminam paulatinamente no terreno social fértil e possuem aderência. Por outro lado, o peso e onipresença da estrutura patriarcal, que mesmo sofrendo abalos sísmicos não se desmantela, promovem refluxos consideráveis. Os contextos sobre os quais foram empenhados esforços reflexivos, comparativos e compreensivos são as Folia de Reis e religiões de matriz africana, especificamente a Umbanda e o Candomblé.

Destarte, podem ser observados dois deslocamentos nas tradições: um que aponta um processo emancipatório das mulheres umbandistas enquanto lideranças dentro da estrutura masculina da Folia de Reis, local onde mulheres de qualquer denominação religiosa, tradicionalmente se mantiveram subjugadas sob a égide do sistema patriarcal; e outro que aponta a perda paulatina de autonomia e liderança das mulheres nos centros e terreiros de Umbanda e Candomblé em relação ao massivo surgimento de lideranças masculinas, espaços em que tradicionalmente as mulheres marcavam e definiam como seu ambiente de agência.

A metodologia empreendida neste trabalho foi de análise bibliográfica associada à observação participante e o uso de fonte oral. De acordo com Amaral (2012, p. 77) dados fiéis e com maior clareza se obtêm observando as manifestações pessoalmente. Não desvalorizando os conhecimentos advindos das descrições e análises encontradas em documentos acadêmicos, cuja relevância também é apontada pela autora. Além disso, Amaral (2012, p.77) evidencia os depoimentos dos próprios participantes como importantes fontes e material de análise para o estudo das manifestações. Pensando nesse tripé metodológico, a observação participante foi imprescindivel para que pudéssemos ter a possibilidade de "dominar, pela vivência, a linguagem e os códigos que orientam o comportamento coletivo e atribuem sentido e plausibilidade às experiências que lá são observadas" (PROENÇA, 2008, p. 31). Para tal, foi necessária a inserção nos contextos sociais pesquisados, observando e analisando, pois as entrevistas não teriam tanta relevância se os contextos onde os colaboradores se articulam não fossem compreendidos em sua dinâmica. Dessa forma, Beaud e Weber $(2007$, p. 120) asseveram que somente algumas entrevistas aprofundadas, isoladas, não bastam, elas devem estar associadas a um conjunto de dados etnográficos, de origem histórica, geográfica, com base em dados estatísticos disponíveis e observações diversas, para que se possa evidenciar toda a sua potência. Por isso, os recursos e dados aos quais tivemos acesso foram utilizados como forma de corroborar e legitimar a análise do quadro que se delineia no campo empírico, mesmo que alguns elementos disponibilizados em um campo não se encontrassem equivalentes no outro. Dados numéricos 
comparativos e tabelas, retirados da produção acadêmica de referência, foram utilizados na análise do contexto das religiões de matriz africana. Dados equivalentes relacionados às Folias de Reis, sobretudo em Leopoldina, ainda não são encontrados em pesquisas acadêmicas, dado inclusive ao ineditismo e atualidade do tema, como um cenário recente que se esboça. Destarte, o estudo deste tema especificamente está focado na observação e em fonte oral.

A partir daí foi lançado o desafio de articular conceitos e dados acadêmicos e as verdades do campo para compreender como as cosmovisões postuladas associadas a aspectos sociais, puderam viabilizar inversões importantes. Tais fenômenos não podem ser desprezados se nos interessa compreender a dinâmica dos deslocamentos positivos e negativos engendrados no processo de empoderamento e autonomia feminina nos ambientes religiosos analisados.

\section{A EMANCIPAÇÃO DA MULHER UMBANDISTA NO ESPAÇO DA FOLIA DE REIS}

A Folia de Reis é uma manifestação artística e cultural, de cunho popular e devocional, bastante expressiva na região da Zona da Mata mineira. É caracterizada tradicionalmente por um cortejo de homens devidamente uniformizados, que a partir do dia 24 de dezembro até o dia 6 de janeiro saem em jornada tocando seus instrumentos e batendo de casa em casa para fazer uma oração cantada e versada, contando a história do nascimento do Menino Jesus e a jornada dos Magos até o seu encontro na manjedoura. Oferece a bênção de sua bandeira, objeto sagrado e de caráter taumaturgo da folia, à família visitada, para que no ano que se inicia a fartura faça morada naquele lar abençoado a partir de então.

Segundo Beaud e Weber (2007, p. 118) a observação é considerada a principal ferramenta etnográfica, e a entrevista é seu complemento. Através das entrevistas e conversas informais, foi possível perceber o alcance de uma fé compartilhada e os interesses que cimentam a relação de devoção. Geertz (2008) ressalta a importância da conversa em pesquisa etnográfica: "O que procuramos, no sentido mais amplo do termo, que compreende muito mais do que simplesmente falar, é conversar com eles" (GEERTZ, 2008, p. 10). Não se trata de tornar-se um nativo, tampouco copiá-lo, mas se inserir no seu contexto cultural, observá-lo, experiênciá-lo e assim obter subsídios para interpretar o sistema entrelaçado de signos, que é a cultura, e descrevê-lo com densidade. Dessa forma, me inseri no universo da Folia de Reis de Leopoldina, participei de tudo que pude, conversei muito, e colhi entrevistas relevantes de mulheres imersas e ativas nesse meio, percebendo suas frustrações e angústias, mas também suas esperanças e atitudes.

Tradicionalmente a estrutura da Folia de Reis é androcêntrica e excludente em relação à participação feminina nas esferas de visibilidade e poder da manifestação. A elas sempre foi delegado os serviços de extensão dos afazeres domésticos nitidamente associados à condição da mulher, como confeccionar/costurar, lavar e passar os uniformes dos foliões e fardas dos palhaços, confeccionar/costurar a bandeira e ornamentá-la, além de fazer sua manutenção ao longo dos anos, ornamentação dos instrumentos, fazer a comida dos jantares oferecidos aos foliões, etc. Cássia, uma de minhas colaboradoras que está ligada a um grupo tradicional e essencialmente androcêntrico e excludente, assegura:

Mulher nunca fez nada na fulia, só trabalho! Lava ropa, passa, lavá sapato, faiz comida! Só trabalha! ${ }^{3}$

3Entrevista realizada com Cássia, em sua residência, no dia 09 de outubro de 2017. 
Além desses serviços invisibilizados, porém fundamentais para o funcionamento dos giros ${ }^{4}$, as mulheres são as agentes que sustentam a manifestação. Pois são elas as principais devotas e promesseiras, ou seja, elas que na maioria das vezes, demandam a visita dos grupos em seu lar, as verdadeiras responsáveis pela manutenção da rede de sociabilidade e vizinhança que sustenta a atividade das folias. Elas que fazem as promessas e oferecem os jantares como pagamento, às vezes por 7 anos ou por uma vida inteira. Até quando mudam de religião, para uma crença menos tolerante ou plural, vai quase que às escondidas levar espórtulas a uma bandeira de Santos Reis que estiver visitando a casa de uma vizinha, para agradecer uma graça alcançada no passado e não deixar de prestar uma reverência5.

Portanto, no contexto tradicional já se pode sinalizar uma participação primordial da mulher para a folia. Dessa forma, analisando de forma segura o histórico de participação feminina nesse contexto androcêntrico, é possivel aferir que sua agência sempre foi inviabilizada, mas jamais nula. Muito pelo contrário, sua contribuição sempre foi indispensável e corroborando inclusive com a clássica divisão do trabalho entre os sexos, que reproduz a tradição patriarcal vigente. Lúcia, uma de minhas colaboradoras que faz parte do mesmo grupo que Cássia, assevera com eloquência, mesmo discordando da ideia do marido, que sem a participação feminina a folia nunca teria saído. Pois as mulheres sempre estiveram nos bastidores impulsionando os giros:

\begin{abstract}
Lúcia: Sempre foi assim! Sempre foi! Sempre teve a participação da mulhé! Marido: Não...

Lúcia: Sempre teve! Porque comé qui, como isso tudo ia acontecê sem a mulhé? Num ixiste! Num tem como! Num ixiste im momento nenhum, im momento nenhum, da História, uma participação, da folia saí, sem a participação da mulhé. [...]por trás é, ué! Num tem como! Sem a participação da mulhé num tem como! Ela só num entra no grupo da folia prá participá! Mas a participação dela, sempre, sempre existiu! Até porque, a bandera. Quem prepara? Quem faz? A mulé! É ela qui costura, é ela que vai amarrá as fitas, é ela que vai enfeitá, são elas que vai fazê! Os instrumento tá lá, vai começa a saí! Quem vai enfeitá, coloca as flores, vê as coisa? A mulé. Tendeu? A participação delas é desde sempre! ${ }^{6}$
\end{abstract}

Segundo Patrícia Birman (1996, p. 207) em função de "uma clássica divisão de trabalho entre os sexos, caberia, pois, às mulheres as lides religiosas e o trabalho doméstico bem como o cuidado das relações familiares". Se a Folia de Reis é ao mesmo tempo uma manifestação religiosa e um coletivo familiar, onde se reúnem pais, filhos, tios, primos, padrinhos, afilhados, compadres, avós e netos, como supor que as mulheres, tradicionalmente presas nas funções de cuidadoras e guardiãs da religião e da família, poderiam estar alijadas desse processo? Portanto,

4Giro é o nome que se dá à jornada da Folia de Reis em si e o período da manifestação da festa, que vai geralmente do dia 24 de dezembro até o dia de Reis, 6 de janeiro. Em algumas folias o giro é estendido até o dia 20 de janeiro, dia de São Sebastião.

5Na pesquisa de campo que realizo desde 2010 pude presenciar uma mulher evangélica beijar e amarrar dinheiro nas fitas de uma bandeira de Santos Reis que estava na casa de sua vizinha. Quando o fez ressaltou que nem podia estar ali, mas não podia deixar de agradecer àquela bandeira. É o sentimento de gratidão superando as fronteiras tênues das religiões no amplo e complexo contexto religioso brasileiro, com seus refluxos e porosidades.

6Entrevista realizada com Lúcia, em sua residência, no dia 10 de outubro de 2017. 
não enxergar a imersão da mulher nesse cenário desde sempre, como ressalta Lúcia, não é só uma injustiça como também um equívoco histórico, que negaria a supremacia do sistema patriarcal na estruturação da sociedade, que de fato foi o que delegou à mulher seu papel submisso, subserviente e atrelado ao ambiente privado e as atividades que ele suscita, assim como seu papel central nas lides religiosas e na família.

A inversão da tradição da Folia de Reis então, não ocorre quando elas são inseridas nesse universo, mas quando elas se inserem nas esferas de visibilidade e poder da folia, lugar onde o seu acesso sempre foi negado, atuando enquanto folionas, participando no cortejo uniformizadas e tendo legitimada a sua sacralidade7. Mas sob qual lacuna da estrutura social emergiu a força que possibilitou a ascensão feminina na Folia De Reis? $O$ que levou as mulheres perceberem a possibilidade de serem donas de grupos até então estritamente masculinos? Qual pré-requisito abriu espaço para que elas almejassem reconhecimento, visibilidade, liderança? Se a sabedoria do povo não se equivoca quando afirma que o que os olhos não veem o coração não sente, em que momento as mulheres viram a possibilidade de liderança e participação ritual e seus corações experimentaram e gostaram desse novo lugar? São questões que só podem ser respondidas historicamente e através da observação sistemática do campo, para compreender em quais contextos a participação feminina extrapola o setor dos serviços e avança para o setor ritual e das sabedorias.

O avanço da agência da mulher nos espaços de visibilidade e poder da Folia de Reis pode ser considerado um fenômeno recente, que vem ganhando força de forma lenta e gradual, começando pelas margens, ou como se diz no popular, comendo pelas beiradas. Tanto que algumas das entrevistadas asseguram que nunca viram mulher na folia ou só viram recentemente. Cássia apontou:

É o que eu tô te falano, dificilmente você vê uma mulher sendo componente duma folia! [...] esse ano é que eu vi numa fulia daqui da roça, essa minina do Zé, que ela tava com o pai dela. O pai dela de palhaço e ela de cantadora de frente. ${ }^{8}$

Matilda, uma devota de Santos Reis que recebe folias em sua casa todos os anos, quando questionada se ela já recebeu ou já viu alguma folia em que a mulher participasse da estrutura ritual, ela respondeu negativamente, embora por fim tenha se lembrado de uma dona de folia:

Eu já vi uma dona da fulia! Mas só que porém, os cara que era os fulião. Só ela que... É a Aparecida Rolinha9! Num sei se ocê conhece, lá da Bela Vista!10

Lúcia, por sua vez, conta que nunca viu, mas já ouviu falar de uma folia composta só por mulheres. Quando questionada sobre a sua posição em relação à participação feminina na folia, Lúcia afirma:

7Os foliões e agora também folionas, são sacralizados/as no ritual de Coroação, que acontece na noite de Natal. Geralmente na casa do dono ou dona da folia, todos os/as participantes recebem a sua coroa (chapéu enfeitado) e a bênção da bandeira, se tornando oficialmente em um/a representante dos Santos Reis, oficialidade concedida pela cultura popular.

8Entrevista realizada com Cássia, em sua residência, no dia 09 de outubro de 2017.

9 Aparecida Rolinha é amiga da Maú, uma das minhas colaboradoras e dona de folia. Embora Matilda não a tenha visto tocar nenhum instrumento, Rolinha sabe, e fez uma participação especial na Folia da Maú tocando pandeiro, quando o grupo foi bater no centro de Omolocô de um amigo de Maú.

10Entrevista com Matilda, em sua residência, dia 13/04/2017. 
Eu acho que poderia e deveria! Eu não sou contra! Eu não! Eu acho que há lugar prá mulher na folia sim! Como se há lugar ... porque hoje assim, a mulher participa de tudo, né?! Então por que não poderia haver... ou até por que... eu já ouvi dizer que tem uma fulia por aí de mulheres. [...] Só de mulheres! Num existe time de futebol só de mulheres, então por que num pode tê uma fulia só de mulheres?! Né?!!!

Embora as entrevistadas deixem transparecer nas falas certo tom de novidade em relação à participação feminina enquanto folionas, todas têm conhecimento do fato. Então se pode pensar que já não é um processo tão novo assim. Pode ainda não ser comum, mas também não pode mais chamado de incomum. Porém, nos contextos onde essa participação não é mais uma novidade, o que pode parecer estranho são os questionamentos em relação ao que é permitido às mulheres na folia. Regina, uma foliona da Folia da Luíza, que integra mulheres nas funções rituais desde sua fundação em 2011, nem entendeu a minha pergunta quando questionada sobre o que as mulheres poderiam fazer na folia. No seguinte excerto da entrevista é possível perceber sua estranheza diante da pergunta:
ABN12: Qual o papel da mulher na folia?
Regina: Como assim?
$A B N$ : Ah, o que elas podem fazer na folia?
Regina: (silêncio) Mas como? Fazê o quê?
ABN: [...] elas podem fazer tudo, ou não?
Regina: Pode, ué! Basta querer!13

\begin{abstract}
A pergunta Ihe soou tão esquisita que pareceu boba, sem fundamento, como quem não acredita que a questão é aquela mesma. Diante da resposta direta de Regina, com um "basta querer!" tão livre e empoderado, isento de quaisquer barreiras próprias do cenário machista, me senti até anacrônica, como se a pergunta fosse baseada em uma realidade do século passado, sem nenhuma aderência ou coerência com o contexto atual. Em sua construção mental, à mulher nada é proibido em relação à sua atuação na folia, pois sua vivência aponta para essa anulação das barreiras androcêntricas que impõem empecilhos à agência feminina. $\bigcirc$ que há de comum entre essas folias onde a atuação feminina não só é tolerada, mas também valorizada e incentivada, se encontra na pertença religiosa majoritária no grupo. São folias que possuem liderança feminina e integra mulheres no cortejo e em outras ações rituais. Luíza, Regina, Maú, Rolinha, todas Umbandistas, Luíza e Regina inclusive eram mães-de-santo. A partir desse ponto em comum, pode-se perceber que no contexto em que essas mulheres se inserem a liderança feminina em coletivos religiosos não é algo novo, moderno, que faça parte de reinvindicações das feministas atuais, pelo contrário, é tradicional. A autonomia feminina para elas não é incomum, famílias matrifocais não fazem parte de uma realidade recente, pelo contrário, é ancestral.

Além disso, em alguns casos pode-se dizer que a estabilidade do grupo faz mais sentido do que a exclusividade masculina. Maú, por exemplo, se manifesta como liderança no momento em que o grupo perdia seu antigo dono e nenhum homem se habilitava a dar continuidade ao projeto. Então ela toma para si a chefia não deixando o grupo cessar suas atividades, hoje é
\end{abstract}

11Entrevista realizada com Lúcia, em sua residência, no dia 10 de outubro de 2017.

12ABN: Andiara Barbosa Neder. Iniciais que representam as minhas falas durante a entrevista.

13Entrevista realizada com Regina, em sua residência, dia 22/06/2019. 
conhecida por todos na cidade e sua folia apontada como referência. Isso faz com que outros grupos encarem como válida a participação de mulheres e passem a considerar tal possibilidade. A partir da atuação das mulheres umbandistas a exclusividade masculina em folias passa a ser relativizada, e outros grupos deixam de ver com estranheza a participação delas, iniciando um processo que Berger (2017, p.21) chama de contaminação cognitiva. Esse processo se estabelece a partir do encontro com o outro, em que ambas as partes se influenciam. Através da relativização os valores do outro podem ser aprendidos, apreendidos e copiados a partir da contaminação cognitiva.

Portanto, interessa compreender através de quais arranjos sociais e a partir de quando as religiões de matriz africana puderam inaugurar uma via de empoderamento feminino no seio de uma sociedade patriarcal e racista. Que se mostra hoje como uma possibilidade de enfrentamento das estruturas androcêntricas da folia. Sendo assim, o deslocamento que as figuras umbandistas realizam na folia a fim de torná-la agregadora das potencialidades femininas em suas esferas de visibilidade e poder, não configuram uma subversão da tradição, mas sim um deslocamento em direção ao retorno da tradição. A escolha desses grupos se manifesta pela supressão da tradição que dita que mulheres não podem participar do cortejo da folia e retomam a tradição de mulheres enquanto lideranças religiosas. Para compreender como se deu esse processo, é preciso retomar historicamente o surgimento das religiões afro-brasileiras e as condições sociais, políticas e econômicas que culminaram na emergência de mulheres enquanto lideranças religiosas, que baliza a discussão a seguir.

\section{AUTONOMIA FEMININA E RELIGIÕES AFRO-BRASILEIRAS: UMA HISTÓRIA DE AFINIDADES ELETIVAS}

Este item propõe se reportar historicamente ao passado colonial e escravocrata brasileiro a fim de analisar a relação de proximidade e, ouso dizer, de simbiose que a condição de autonomia de mulheres negras estabeleceu com sua religiosidade que culminou no surgimento do que hoje conhecemos como religiões de matriz africana. Atuando com liberdade e protagonismo a revelia das punições impostas a seu modo de vida, mulheres negras, mulatas e pardas, africanas ou afrodescendentes, se utilizaram das normas e valores do próprio sistema, para legitimar suas ações. Utilizando seus corpos com a liberdade que a recente alforria thes conferia, foram taxadas de devassas e mal procedias, acusadas de fazer mau uso dos seus corpos e de aliciar outras mulheres de mesma condição, além de serem condenadas pela Igreja por, no entendimento católico, fazerem pacto com o demônio. Paradoxalmente, todo esse contexto de julgamentos e de maior opressão sobre a figura da mulher negra livre ou liberta e empobrecida, fomentou o reaparecimento de uma autonomia feminina africana perdida, aplacada ou adormecida pela diáspora. Dessa forma, o histórico embrionário das religiões de matriz africana se estrutura a partir de várias afinidades femininas: afinidade com a chefia de seus lares, afinidade com a autonomia de suas vidas, afinidade com a religiosidade africana, afinidade com outras mulheres em mesma condição de existência, enfim, afinidades múltiplas e estruturantes de uma condição que culminou na formação da religião que conhecemos hoje como Umbanda, Candomblé entre outras.

A expressão afinidades eletivas possui uma trajetória anterior ao seu uso sociológico. Segundo Löwy (2011, p.130) o termo afinidade foi cunhado ainda no período medieval e seu uso estava atrelado à alquimia para explicar a atração e fusão dos corpos. No século XVIII a afinidade 
é apregoada como "a força em virtude da qual duas substâncias diversas 'se procuram, unem-se e se encontram' em um tipo de casamento"(LÖWY, 2011, p.130). Ainda no século XVIII, porém em sua segunde metade (1775) o termo afinidades eletivas finalmente aparece, na obra de um químico. No século XIX Goethe toma emprestado o termo das ciências naturais e o aplica na literatura, intitulando um romance. Nele o termo é utilizado como uma metáfora para assinalar como se dá o movimento pelo qual um homem e uma mulher são atraídos mutuamente, através de uma afinidade íntima entre suas almas. $O$ termo, a partir de então, passa a ser difundido na cultura alemã designando um tipo particular de ligação entre espíritos. Já no século XX, o termo é mais uma vez transposto agora para o terreno das ciências sociais por Max Weber, mantendo o sentido de escolha recíproca, atração e combinação (LÖWY, 2011, p.131). Weber não conceitua o termo em nenhuma de suas obras onde o citou. $O$ autor $\mathrm{o}$ utilizou primeiramente enquanto uma metáfora, retomando como comparativo a obra de Goethe, por isso, inicialmente colocou aspas em tono da expressão, que logo a seguir já caiu, se tornando então um conceito sociológico, que não precisava de maiores explicações por ser naturalmente entendido, já que a obra de Goethe era de domínio comum na Alemanha. Embora não conceitue, oferece explicação sobre o funcionamento, exemplificando que quando um sistema social e um espírito cultural estão ligados através de um grau de adequação intenso, eles entram em estado de afinidades eletivas e se adaptam ou se assimilam mutuamente até enfim, formarem uma unidade sólida (LÖWY, 2011, p.137). A partir da observação da utilização do termo por Weber, Löwy (2011, p.139) se propõe a conceituá-lo da seguinte forma:

afinidade eletiva é o processo pelo qual duas formas culturais - religiosas, intelectuais, políticas ou econômicas - entram, a partir de determinadas analogias significativas, parentescos íntimos ou afinidades de sentidos, em uma relação de atração e influência recíprocas, escolha mútua, convergência ativa e reforço mútuo.

Löwy (2011, p.140) ainda acrescenta que se trata de uma espécie de simbiose cultural, onde mesmo que os elementos permaneçam distintos estão organicamente associados. $\dot{E}$ exatamente essa a relação entre autonomia feminina estabelece com o nascimento das religiões de matriz africana. Em seu estágio ainda embrionário, porém mais sistematizado do que se apresentava nas senzalas, essas religiões se desenvolveram com o estabelecimento de uma troca cultural mais rica e intensa, alcançando outros atores e nichos sociais, que não somente os negros escravizados. Assim ganharam maior visibilidade urbana, que incomodava a elite colonial de maneira mais incisiva.

Apesar da estrutura social em significativas regiões da África ser focada na figura masculina e o poder religioso estar nas mãos dos homens, as mulheres inseridas nesses escopos sociais detinham uma autonomia e independência com as quais o casamento poligâmico corroborava. Sobre a autonomia e relevância das mulheres nas atividades mercantis ainda na África, Bernardo $(2005$, p.10) assevera:

autonomia feminina que veio sendo conquistada desde a África, onde as mulheres foram as principais responsáveis pela rede de mercados que interligavam todo o território iorubá, com experiência de excelentes comerciantes, atribuída também às mulheres bantas.

O casamento poligâmico possibilitava às mulheres além de certa independência financeira e física em relação aos maridos, também sua autonomia 
para chefiar um lar, já que somente a primeira esposa morava sob o mesmo teto que o marido (BERNARDO, 2005, p.10). A independência financeira se dava na medida em que elas compravam os produtos dos maridos e ficavam com os lucros das vendas (BERNARDO, 2005, p.2). A matrilinearidade religiosa também se colocava como preponderante na educação religiosa dos filhos, pois as mães tinham um vínculo afetivo e presencial com as crianças muito maior que o pai (BERNARDO, 2005, p.12). O casamento poligâmico também suscitava indiretamente o desenvolvimento de habilidades religiosas, pois a rivalidade entre as esposas era motivo de ataques frequentes através da manipulação do plano espiritual (BERNARDO, 2005, p.14). Tais características sociais africanas influenciaram o desenvolvimento de uma cultura matrifocal difundida entre as herdeiras negras no Brasil, subvertendo inclusive a lógica do poder religioso focado em mãos masculinas.

As características de proteção e afeto maternos intensos, acrescidas à de provedora, que a mulher africana e afro-descendente também detém, [...] possibilitam a vivência da matrifocalidade na sociedade brasileira. [...] esses aspectos culturais, sócio-econômicos e históricos elencados [...] dão indícios fundamentais para o entendimento do fato peculiar da mulher surgir como a detentora do poder religioso (BERNARDO, 2005, p.15).

De acordo com Löwy (2011, p. 140) a afinidade eletiva é estimulada ou prejudicada por condições históricas. Ou seja, é preciso um determinado conjunto de fatores históricos, sociais e culturais para que se desenvolva um processo de atração mútua, de afinidade eletiva. Nesse sentido, já elucidados os fatores que influenciaram o modo de ser das africanas no Brasil e que foi transmitido às suas descendentes, é possível mostrar como as condições históricas, econômicas, sociais e culturais do Brasil Colônia preparou uma ambiente prolífico para que surgissem as afinidades eletivas entre o nascimento das religiões afro-brasileiras e a autonomia feminina.

Como negras de ganho, as escravizadas conseguiam juntar dinheiro para comprar a própria alforria de seus descendentes. Lisa Oliveira (2017, p. 234) assevera que o comércio de gêneros alimentícios, empreendido por mulheres pretas e mestiças no Brasil, correspondia ao papel feminino na produção de comida e nas transações mercantis conferidas nas sociedades africanas tradicionais. No Brasil, ampliaram ainda a gama de possibilidades de inserção no mercado de trabalho livre que se delineavalit. E a possibilidade de alforria para as mulheres era muito maior do que para os homens:

Essas atividades comerciais recriadas no Brasil ainda na época da escravidão fazem com que surjam as ganhadeiras, escravas ou livres, que em muitas regiões tornam-se as responsáveis pela distribuição dos principais gêneros alimentícios, chegando a comprar a própria alforria, numa forma de liberdade que, por sua vez, beneficiou muito mais as mulheres, que eram menos necessárias à produção sobre a qual o sistema escravocrata estava constituído. Assim, as mulheres negras, comparadas com seus parceiros, tiveram

14Elas ganhavam dinheiro como amas, lavadeiras, cozinheiras, vendiam quitutes em seus tabuleiros, com a prática de curandeirismo através de seus conhecimentos com as ervas, outras se prostituíam, algumas eram sustentadas por homens com quem mantinham relacionamentos extraconjugais, e em muitos casos, exerciam mais de uma função concomitantemente, a fim de complementar a renda (OLIVEIRA, 2017, p. 235). Tinham filhos, provenientes dos relacionamentos nem sempre duradouros, e em outros casos pelo exercício das práticas sexuais de onde tiravam seu sustento. 
melhores oportunidades de trabalho, construindo brechas no mercado de trabalho livre que então se formava (BERNARDO, 2005, p. 10).

Nessa nova condição de existência, a matrifocalidade para essas mulheres não era considerada algo ruim, que lhe imprimia sofrimento, ou um fardo pesado a se carregar. Pelo contrário, evidenciava sua autonomia e conferia satisfação a elas (BERNARDO, 2005, p. 11). Nesse sentido, somente a presença dessas mulheres livres e libertárias no seio de uma sociedade machista, escravocrata e racista já se dava por si só como uma contradição incômoda aos setores dominantes da sociedade. Mas além dessa contradição primeira, havia uma segunda ainda mais potente, que pode ser compreendida quando se analisa a figura dessa mulher enquanto objeto sexual. Essa imagem, que é fruto da visão racista e androcêntrica cristalizada na sociedade, e que possuía um lugar bem definido nas relações de poder cristãs patriarcais, viabilizava não mais uma via de submissão, como se poderia supor. Essas mulheres conseguiam, a partir dessa reificação vil, a superação da submissão. A elas não era imputada a "graça" do casamento monogâmico tridentino, como às mulheres brancas e de classe social elevada. Por isso, possuíam autonomia de movimentos e participação nas manifestações culturais, jamais vislumbradas pelas mulheres endereçadas ao casamento (OLIVEIRA, 2017, p. 219). Dessa forma, a contradição emerge da subversão das regras e valores próprios da sociedade patriarcal no momento em que eles próprios eram incorporados por elas. Ou seja, de dentro do sistema e a partir de seus valores mais caros, elas conseguiam engendrar rupturas e ser o ponto nevrálgico dessa estrutura.

\begin{abstract}
Eram nos ambientes das casas de alcouce, nas uniões consensuais e nas relações transitórias que negras, mulatas e brancas pobres incorporavam ao seu modo as relações culturais patriarcais ao improvisarem papéis informais de resistência que se caracterizaram, sobretudo, pela negação ao estrito comportamento social ditado pela Igreja Católica. Mulheres pobres não necessitavam da submissão resultante das restrições relativas ao casamento tridentino (OLIVEIRA, 2017, p. 219).
\end{abstract}

Nesse sentido, suas condições de vida e sustento não lhes eram favoráveis sob as lentes da sociedade racista e patriarcal afinada e reafirmada pelo discurso católico. Apesar de toda condenação, elas avançaram no sentido de alcançar a autonomia feminina. $E$ não foi apenas uma consequência da condição sócia econômica vigente, mas também uma escolha consciente. Bernardo $(2005$, p. 10) assevera que a matrifocalidade não foi só uma imposição da escravidão e do contexto do pós-abolição por conta da marginalização do homem negro no mercado livre durante as primeiras décadas do século $\mathrm{XX}$, que o impedia de assumir a chefia de uma família e de um lar. Mas a essas condições se associou à vontade da mulher de ser autônoma, independente e verdadeiramente livre fora do cativeiro.

Para Weber as afinidades eletivas não se sustentam a partir de uma relação causal, a escolha ativa é preciso estar presente, a atração recíproca (LÖWY, 2011, p.139). Elas escolheram ser livres, chefiar seus lares e se apresentar como lideranças religiosas. Nesse cenário, as redes de solidariedade entre mulheres na mesma condição emergiam como possibilidade de auxílio mútuo e uma resistência não programada, mas criada a partir das próprias condições diárias. Oliveira (2017, p. 218) afirma sobre "a constituição de vínculos de auxílio mútuo através do 'mau procedimento' nos fogos chefiados por mulheres sós". Estranhamente, em um cenário social excludente, racista e patriarcal, a religiosidade de matriz africana delineou um espaço socialmente 
expressivo e incômodo aos setores dominantes, onde a centralidade feminina se tornou notável e necessariamente estruturante desses espaços.

De acordo com Oliveira (2017, p. 204-205) o temor de rebeliões e insurreições de escravos e libertos era uma constante entre a classe dominante, pois entre meados do século XVIII e princípio do XIX a população negra e mulata correspondia a $75 \%$ do total da população mineira. A possibilidade de alforria era uma estratégia de controle eficiente na prevenção das revoltas. A liberdade muitas vezes estava condicionada à repressão da herança cultural africana e adoção do cristianismo. Segundo Oliveira (2017, p 186) o discurso cristão dominante maldizia os batuques e suas danças, pois era preciso investir uma luta contra os rituais mágicos e danças profanas, visto que as feiticeiras e curandeiras eram líderes religiosas e possuíam prestígio no seio da comunidade negra. Em seus lares matrifocais negros de diversas origens culturais mesclavam suas referências étnicas e religiosas e fortaleciam suas culturas.

Os negros superaram as diversidades culturais por meio dos batuques e calundus realizados nos domicílios matrifocais, que constituíram os principais centros de práticas sexuais ilícitas, o que expressa a importância das 'mal-procedidas' na manutenção de uma cultura de resistência à escravidão (OLIVEIRA, 2017, p. 205).

Esse histórico, que desvela uma trajetória de resistência das mulheres negras e seu proeminente papel na manutenção e recriação das suas tradições religiosas e de suas antecessoras, explica o perfil das líderes de templos de religiões de matriz africana hoje ser formado por mulheres independentes e solteiras. Segundo Nilza Menezes (2012, p. 110) nos terreiros em que a liderança é feminina, "foi possível observar que as sacerdotisas estabelecidas são independentes financeiramente e, geralmente, não possuem maridos".

Os terreiros por muito tempo foram vistos como um espaço de liderança e emancipação feminina e ainda hoje são ambientes onde a supremacia feminina se mostra expressiva (CORDOVIL, 2014, p. 117-118). Apesar de nesses espaços as mulheres serem notoriamente mais livres, os valores androcêntricos não são anulados, são assimilados, mas isso ainda hoje, só faz emergir mais afinidades eletivas. Segundo Carneiro (2008, p. 111):

antigamente, o candomblé era, nitidamente, um ofício de mulher. Indicam-se entre outras coisas, a necessidade de cozinhar as comidas sagradas, de velar pelos altares, de enfeitar a casa por ocasião das festas, de superintender a educação religiosa das mulheres de crianças - serviços essencialmente domésticos.

Com todas as reproduções do modelo de sociedade patriarcal vigente, no que diz respeito ao ambiente doméstico e familiarl5 ser de domínio e responsabilidade da mulher, valeram-se dos tradicionais trabalhos femininos para firmarem seu lugar no contexto religioso.

Ainda que nos terreiros de Candomblé a liderança e supremacia feminina sejam mais notáveis que nos centros umbandistas, entre outros fatores por uma questão dogmática ancestral

15As religiões afro-brasileiras de fato possuem um tratamento e uma estrutura familiar, como pai, mãe, filha de santo. Mesmo que essas expressões para alguns candomblecistas não sejam muito bem quistas, até no idioma iorubá se tem expressões ialorixá e babalorixá que significam respectivamente, mãe e pai de santo. Assim como no Candomblé de Angola e do Congo, se tem a mameto de inquice (mãe) e tata de inquice (pai) (CARNEIRO, 2008, p. 110). 
do Candomblé, a Umbanda também possui um número expressivo de mulheres ocupando o mais alto cargo na hierarquia dos centros. De acordo com uma ordem social de ancestralidade africana, tradicionalmente somente as mulheres possuem legitimidade para entrar em transe (BASTIDE, 2001). Essa legitimidade feminina tem suas raízes na estrutura religiosa iorubá. "Os iorubás, que faziam ligação entre África Ocidental e a África Bantu, cultuavam forças femininas do cosmos, que retornavam para o bem da comunidade por meio do poder inato das mulheres" (OLIVEIRA, 2017, p. 199). Portanto, o poder feminino era supervalorizado nos rituais, às vezes até mesmo superando o dos ancestrais (OLIVEIRA, 2017, p. 199). Dessa forma, o poder religioso que na África estava concentrado nos homens, no Brasil se transfere para as mãos femininas, e essa transferência "pode ser melhor explicitada ao recolocar a noção de Terra-Mãe, iluminando a necessidade da mãe, da mulher, da proteção feminina para os africanos ao deixarem a sua terra natal - a África" (BERNARDO, 2005, p.19). Portanto, a marcante presença feminina chefiando os espaços de culto das religiões afro-brasileiras, em um primeiro momento, se deu através das mulheres negras forras, na maioria das vezes não casadas, refazendo suas vidas nos centros urbanos.

\section{PERDA DE ESPAÇO E PODER FEMININOS NOS CENTROS E TERREIROS DE UMBANDA E CANDOMBLÉ}

O surgimento das religiões afro-brasileiras está intimamente ligado ao contexto da escravidão, no qual os africanos foram retirados do seu país de origem e trazidos para o Brasil pelo colonizador para desempenhar múltiplas funções. Os africanos se tornaram a principal mão de obra nas lavouras, na casa dos senhores de engenho, mais tarde nas minas de ouro descobertas principalmente em Minas Gerais e também desenvolvendo tarefas na área urbana, trabalhando como escravos de ganho'6. Segundo Berkenbrock $(2012$, p. 62) do ponto de vista histórico, a África é o campo de origem e o Brasil o campo de desenvolvimento das religiões afro-brasileiras. As religiões africanas formam a base teológica, a partir do qual se desenvolveram as religiões afro-brasileiras.

Importa salientar a relevância da liderança das mulheres na constituição do Candomblé, sobretudo as de origem iorubá. A mulher como ser fundante e como ocupante do cargo máximo dentro dessa hierarquia religiosa tornou-se um importante assunto a ser pesquisado, principalmente por aqueles que se dedicam ao estudo sobre gênero. Posteriormente a liderança feminina foi basilar também no surgimento da Umbanda, uma religião tipicamente brasileira, que se formou a partir do sincretismo religioso.

No que se refere à hierarquia dentro dos contextos religiosos e na mitologia que dá base ao candomblé e à umbanda, a mulher está, em muitos casos, acima do homem, por diversas questões, entre elas a dogmática e a tradição. $O$ que reverbera ainda hoje em grande parte espaços religiosos afro-brasileiros. A pioneira nesse tipo de discussão foi Ruth Landes (1967),

16Segundo Berkenbrock $(2012$, p.81) os africanos eram emprestados para prestarem determinados serviços ou então enviados de casa em casa por seu dono para oferecerem serviços ou venderem algum produto. Muitos deles eram trabalhadores especializados. O lucro ou uma determinada soma combinada anteriormente deveria ser entregue aos donos. Estes escravos gozavam de uma determinada liberdade, se comparada à condição dos escravos do campo. Entre os escravos urbanos houve melhores condições para a transmissão de cultura. 
que argumentou a respeito das relações de gênero "transgressoras" que predominavam nos cultos afro-brasileiros e que colocavam as mulheres em funções centrais nas casas religiosas.

Em relação à chefia feminina importa destacar alguns fatores que foram incisivos para que a mulher viesse a ocupar o ápice da hierarquia religiosa, além dos outros que foram elencados no trajeto feminino da África para o Brasil. Fato assim comentado por Bernardo, (2005, p.16):

As mulheres africanas pertencentes a etnias fons e iorubás exerceram em seus respectivos reinos um poder político importante. É claro que no presente da escravidão esse poder teve que ser ressignificado. Na realidade é totalmente contraditório com a situação de escravo o exercício de qualquer poder no plano do real. Assim, pode ter ocorrido uma transformação: se não existiam condições de exercício do poder real, exercia-se no plano do imaginário, através da religião.

Ao contrário do que acontece em grande parte das crenças, onde a figura masculina ocupa o maior posto dentro da hierarquia religiosa, nas religiões de matriz africana, as mulheres desafiaram a sociedade patriarcal, se firmando como lideranças, gerindo com sucesso todas as etapas de formação, organização e gerenciamento dos terreiros. Em outros contextos religiosos as mulheres não atuam nos papéis principais, por isso torna-se tão significante compreender o papel de atuação das mulheres africanas na constituição das religiões afro-brasileiras. Se fizermos um retorno e analisarmos os contextos religiosos percebemos que na grande maioria o homem aparece como figura central. Rosado-Nunes (2005, p. 363) aponta:

Historicamente, os homens dominam a produção do que é 'sagrado' nas diversas sociedades. Discursos e práticas religiosas têm a marca dessa dominação. Normas, regras, doutrinas são definidas por homens em praticamente todas as religiões conhecidas. As mulheres continuam ausentes dos espaços definidores das crenças e das políticas pastorais e organizacionais das instituições religiosas. O investimento da população feminina nas religiões dá-se no campo da prática religiosa, nos rituais, na transmissão, como guardiãs da memória do grupo religioso.

Quando os homens perceberam toda a credibilidade e poder confiado às mulheres dentro dos terreiros começaram a tomar as iniciativas para adentrar enquanto lideranças, esse espaço sagrado . Carneiro (2008), não considera justa a entrada dos homens no candomblé, sendo para ele desmoralizadora a maneira pela qual o sexo masculino adentrou a religião. $\bigcirc$ autor aponta que os homens usurparam os saberes femininos que foram construídos e estruturados ao longo de anos de preparo dentro das tradições religiosas de matriz africana. Assim como Carneiro (2008), Lagos (2012) também defende a importância das mulheres nos terreiros e não descreve positivamente a ação dos homens nesses espaços sagrados. Segundo a autora quando a mulher é sacerdotisa chefe, geralmente ela é organizada, domina e controla tudo, participa de todas as esferas, tanto organizacionais quanto rituais, coordenando de maneira holística o espaço. Já nas casas dirigidas por homens, eles mandam fazer e não fiscalizam. Dessa forma, os serviços nem sempre são feitos como deveriam e a desorganização, pode comprometer 
a dinâmica da casal7, uma vez que todos os rituais são voltados para trocas de energias entre o Aiê (terra) e o Orum (céu) a manipulação equivocada de qualquer elemento dentro do terreiro pode provocar desiquilíbrio entre o mundo espiritual e o mundo terreno.

Enquanto Lagos (2012) faz uma observação sobre o domínio das mulheres em todos os aspectos religiosos e organizacionais que envolvem uma casa de santo, Carneiro (2008) faz uma referência à importância dos saberes tradicionais dominados pelas mulheres sendo usurpados pelos homens, que em algumas ocasiões não possuem experiência suficiente para manter vivos os conhecimentos necessários para conduzir uma casa de candomblé. É relevante mencionar que como no candomblé não existe um livro sagrado. É a experiência, o conhecimento e a vivência no espaço do terreiro que mantêm vivas as tradições religiosas afro-brasileiras.

O poder e a visibilidade advindos dos terreiros enquanto espaços sagrados passaram a despertar o interesse dos homens que começaram a procurar meios para se inserirem como lideranças (babalorixá), nesses contextos religiosos, que outrora eram predominantemente femininos. O chamado dos orixás, as doenças e perturbações espirituais, a possibilidade de ascensão social e a realização financeira são motivos que corroboram para a inserção do homem nos terreiros. Muitas vezes a inexperiência dos homens, sua chegada ao terreiro sem passar pelo processo de feitura, colocam em xeque a credibilidade das religiões afro-brasileiras, que são alvos constante do chamado racismo religioso.

Pesquisas e estatísticas vem demonstrando como os homens estão ocupando os lugares que antes eram exclusivamente dominados pelas mulheres. Utilizamos a pesquisa feita em três localidades diferentes para exemplificar essa ascensão masculina dentro: dos terreiros de candomblé.

\begin{tabular}{|lll|}
\hline $\begin{array}{l}\text { Cidades e números } \\
\text { totais de terreiros } \\
\text { Juiz de Fora (2000) }\end{array}$ & $\begin{array}{l}\text { Terreiros dirigidos } \\
\text { por Homens }\end{array}$ & $\begin{array}{l}\text { Terreiros dirigidos por } \\
\text { Mulheres }\end{array}$ \\
$\begin{array}{l}23 \text { terreiros } \\
\text { João Pessoa (2009) }\end{array}$ & 16 & 11 \\
$\begin{array}{l}28 \text { terreiros } \\
\text { Rio de Janeiro }\end{array}$ & 19 & 12 \\
(2015) 33 terreiros & & 14 \\
\hline
\end{tabular}

Tabela 1: relação comparativa entre número de terreiros liderados por homens e mulheres nas respectivas localidades.

Os dados acima foram colhidos nas pesquisas feitas em Juiz de Fora por Maria da Graça Floriano (2000), em João Pessoa por Bastos (2009) e no Rio de Janeiro por Pereira (2015). Percebe- se que gradativamente os homens vêm conseguindo conquistar a liderança dentro dos terreiros de candomblé. Mas um dado merece ser mencionado, enquanto em vários terreiros a matrilinearidade vem perdendo espaço, na Casa Branca, uma das mais tradicionais de Salvador,

17Como as generalizações podem representar armadilhas perigosas para a pesquisa acadêmica, a observação de Lagos (2012) não deve ser tomada como base para descrever a realidade de todos os terreiros chefiados por homens. Por outro lado, também não deve ser negligenciada, visto que parte de uma observação criteriosa, que descreve os aspectos mais comuns em relação às casas de liderança feminina e masculina, não configurando uma totalidade irrefutável. 
não há iniciação de homens com objetivo de assumir a cadeira como babalorixá, há somente iniciação de ogãs. Mesmo assim é notória a inversão de valores: as mulheres vem perdendo espaço para os homens dentro de um contexto religioso que a mesma foi reconhecida como ser fundante. A crescente participação do elemento masculino nessas religiões é explicada em parte pela mudança de contexto social dessas religiões na atualidade. Hoje, o homem negro não mais se encontra no cativeiro, impedido de protagonizar a cena cultural e religiosa, e tão pouco hoje tais religiões só são cultuadas por negros. Diante disso, o ambiente social atual possibilitou a participação masculina, como no passado possibilitou a ascensão feminina enquanto liderança, a partir de afinidades eletivas. E assim como as mulheres no passado, os homens não hesitaram em tomar tal oportunidade para si, por conta dos vários fatores já elencados. Dessa forma, o sistema patriarcal que se manteve dominante, reverberou de fora para dentro, da sociedade para os terreiros e centros, e as mulheres assistem aparentemente em conformidade tal transmutação.

Assim como o machismo encontrou um canal de acesso para as religiões afro-brasileiras, o feminismo encontrou uma via de acesso às Folia de Reis. Percebemos que enquanto no contexto da Folia de Reis as mulheres têm conseguido ascender ocupando papéis de destaque, nas denominações de matriz africanas como a Umbanda e o Candomblé os homens têm chegado e ocupado o cargo de chefia que até então era algo estritamente feminino.

\section{CONCLUSÃO}

Através de uma análise histórica foi possível perceber as mulheres de origem africana como precursoras na reinvenção da sua forma de crer dentro do hostil ambiente da escravização no Brasil. Os primeiros terreiros de que se tem notícia, datando dos séculos XVIII e XIX, são os candomblés de origem iorubá, cuja chefia é feminina, embora uma proto-Umbanda já vinha tomando forma nos batuques e calundus das casas matrifocais nas Minas setecentistas. Mesmo sob a imposição dos costumes do colonizador europeu as mulheres souberam preservar e enriquecer seus costumes, seus idiomas, sua cultura e seu modo de reverenciar os deuses. Em contrapartida também souberam acrescentar aos seus hábitos religiosos elementos do catolicismo e da cultura indígena, ampliando ainda mais suas possibilidades de recriar no Brasil as suas práticas religiosas.

As mulheres negras resistiram, e através da formação de afinidades eletivas entre as embrionárias religiões afro-brasileiras nesse momento e a autonomia feminina resgatada e ressignificada, reinventaram dentro do contexto da escravização o seu modo de vida e de se relacionar com poder, abrindo uma via de empoderamento da mulher negra em uma sociedade patriarcal, racista e classista. Aproveitaram suas habilidades desenvolvidas, principalmente como cozinheiras e negociantes, para buscarem recursos econômicos visando sua liberdade. Foram capazes de desafiar a sociedade patriarcal se estabelecendo como fundadoras e ocupantes do cargo mais alto existente dentro da hierarquia religiosa afro-brasileira.

Por questões próprias do modelo escravocrata, as mulheres conseguiam juntar pecúlios e conquistavam sua alforria antes dos homens. Juntamente com a liberdade alcançada, foram surgindo as primeiras casas de religião de matriz africana no Brasil. Tradicionalmente nas grandes religiões a liderança é algo pertencente aos homens. Por outro lado, o topo da hierarquia religiosa ocupada por mulheres é uma realidade constatada nos terreiros de umbanda e candomblé. Em uma sociedade onde as mulheres eram vítimas da opressão masculina, da violência

\section{1}


e da invisibilidade, elas se tornaram empoderadas, respeitadas e veneradas por conta da autoridade que exerciam.

Dentro das religiões de matriz africana atualmente tanto homens quanto mulheres podem assumir o posto hierárquico mais alto. Porém, por muito tempo as mulheres, se estabeleceram como lideranças únicas dentro dos terreiros e ate hoje em candomblés tradicionais da Bahia não é permitido aos homens ocuparem o cargo de chefia (babalorixá). As mulheres são consideradas as principais guardiãs dos saberes elementares para a existência das religiões afro-brasileiras. Mas a revelia disto parece estar se consolidando como uma tendência a ascensão masculina enquanto liderança nas religiões afro-brasileiras.

Estatisticamente nota-se que em muitos terreiros de Umbanda e Candomblé os homens estão ocupando um espaço que era estritamente feminino. Em contrapartida percebemos um movimento oposto nas Folias de Reis, onde o homem que tradicionalmente se estabelecera como figura principal, está dividindo espaço com as mulheres que ficavam invisibilizadas nos bastidores deste contexto religioso. Um fato marcante explanado é que dentro da folia de pertença umbandista as mulheres conseguem conquistar seu espaço para além da invisibilidade dos trabalhos domésticos, como extensão do que realizam no ambiente privado. Logo, a autonomia confiada às mulheres no espaço sagrado dos terreiros está migrando para o contexto da folia e conferindo a elas poder e visibilidade.

$\mathrm{Na}$ atualidade a mulher ocupa espaços de visibilidade a ela sempre negados. Nas folias de pertença umbandista as mulheres se inserem no cortejo, possuem funções rituais definidas e são lideranças dos grupos. Liderança que não pode ser observada nas folias de pertença católica onde o patriarcalismo ainda fala mais alto conferindo aos homens o posto de liderança.

Tratar de dois contextos distintos, mas que dialogam entre si, nos permitiu perceber uma inversão de valores tradicionais: nas religiões de matriz africana os homens vêm adentrando um espaço de domínio até então feminino enquanto na folia de pertença umbandista a superioridade masculina vem sendo paulatinamente diluída pela presença das mulheres nas esferas de visibilidade e poder. O campo religioso brasileiro é muito dinâmico, por isso suscita deslocamentos de diversos fenômenos religiosos e sociais. $\bigcirc$ que sugere um movimento de fluxo e refluxo, construção e desconstrução, revelando valores aparentemente antagônicos em espaços simbolicamente improváveis em que insistem em se inserir, e o fazem com êxito.

\section{REFERÊNCIAS}

AMARAL, Rita. Festa à brasileira. o significado de festejar no país que "não é sério". Tese de Doutorado apresentada ao Departamento de Antropologia da Faculdade de Filosofia, Letras e Ciências Humanas da Faculdade de São Paulo. Disponível em: http:/ / www.teses.usp.br/teses/disponiveis Acesso em: 27 fev. 2014.

BASTIDE, Roger. Os Candomblés da Bahia. São Paulo: Companhia das Leras, 2001.

BASTOS, Ivana Silva. A visão do feminino nas religiões Afro-brasileiras. CAOS - Revista Eletrônica de Ciências Sociais, n. 4, Setembro/2009 
BEAUD, Stéphane, WEBER, Florence. Guia para pesquisa de campo. como produzir e analisar dados etnográficos. Tradução de Sérgio Joaquim Almeida; revisão de tradução de Henrique Caetano Nardi. Petrópolis, RJ: Vozes, 2017.

BERKENBROCK, Volney. A experiência dos orixás. um estudo sobre a experiência religiosa no candomblé. $4^{a}$ ed. Petrópolis: Vozes, 2012.

BERNARDO, Teresinha. O Candomblé e o poder feminino. Revista Estudos de Religião, n.2, 2005, p. 1-21.

BIRMAN, Patrícia. Mediação feminina e identidade pentecostal. Cadernos Pagu, n. 6-7, Campinas, p.201-226, 1996.

CARNEIRO, Edson. Candomblés na Bahia. $9^{\circ}$ ed. São Paulo: Editora WMF Martins Fontes, 2008. (Raízes)

CORDOVIL, Daniela. Religiões afro. introdução, associação e políticas públicas. São Paulo: Fonte Editorial, 2014.

FLORIANO, Maria da Graça. Tradição e invenção: candomblé e umbanda no campo religioso de Juiz de Fora. In. DAIBERT, Robert Júnior; FLORIANO, Maria da Graça; BERKENBROCK, Volney José (orgs). A mão que costura o vento. mediações do sagrado nas tradições religiosas afro-brasileiras. Juiz de Fora: Ed.UFJF/MAMM, 2015.

GEERTZ, Clifford. A Interpretação das Culturas. Rio de Janeiro, LCT, 2008.

LAGOS, Nilza Menezes Lino. Segredos e intrigas. Relações entre violência e o processo de masculinização nas lideranças das práticas religiosas afro-brasileiras em Porto Velho - RO. 219 F. Tese (Doutorado em Ciências da Religião). Faculdades de Humanidades e Direito da Universidade Metodista de São Paulo. São Bernardo do Campo, 2012.

LÖWY, Michael. Sobre o conceito de "afinidade eletiva" em Max Weber. Tradução de Lucas Amaral de Oliveira e Mariana Toledo Ferreira. PLURAL, Revista do Programa de Pós -Graduação em Sociologia da USP, São Paulo, v.17.2, 2011, pp.129-142

MENEZES, Nilza. A violência de gênero nas religiões afro-brasileiras. João Pessoa: Editora Universitária da UFPB, 2012, 208 p.

OLIVEIRA, Lisa Batista de. Devassas e "mau-procedidas": prostituição, concubinato e vivência religiosa nas Minas Gerais do século XVIII. Curitiba: Editora Prismas, 2017.

PEREIRA, Rodrigo. As transformações nos matriarcados nagôs nos candomblés no estado do Rio de Janeiro (séculos XX e XXI): a figura dos homens no comando dos axés. Revista Espacialidades, v. 8, n. 1, 2015.

\section{3}


PROENÇA, Wander de Lara. Observação participante. Revista Antropos, vol.2, Ano 1, maio de 2008.

ROSADO-NUNES, Maria José. Gênero e religião. Revista Estudos Feministas, Florianópolis, v. 13, n. 2, 2005, p. 363-365, maio-agosto 2005. 